\title{
VULNERABILIDADE NO MUNICÍPIO DE JARAGUÁ DO SUL SC: ESTUDO DOS EFEITOS DAS CHUVAS DE 2008
}

Felipe Amaro da Silva ${ }^{1}$

André Luiz Pinto ${ }^{2}$

Resumo: O Município de Jaraguá do Sul vem sofrendo ao longo dos anos pelos constantes desastres ambientais, nesse estudo priorizou-se o caso do ano de 2008. O Município localiza-se, em um vale da Serra do Mar que apresenta vulnerabilidade a processos naturais de desnudação que, dadas as condições climáticas, geológicas, geomorfológicas e de ocupação antrópica aumentam o risco de ocorrências de desastres naturais como inundações e movimentos de massa. O município de Jaraguá do Sul declarou situação de emergência em 20 de novembro de 2008 e, posteriormente Estado de Calamidade Pública em 14 de dezembro do mesmo ano.

Palavras-chave: Jaraguá do Sul. Desastres Naturais. Evento Climático Extremo.

\footnotetext{
${ }^{1}$ Geógrafo pela Universidade Federal de Mato Grosso do Sul - UFMS campus de Três Lagoas Título de Bacharel em Geografia. Mestrando em Geografia pela UFMS. Av. Ranulpho Leal 3484 - Três Lagoas - MS. CEP 79610-100. Endereço Eletrônico: felipeamaro25@hotmail.com.

2 Professor Doutor, Docente da Universidade Federal de Mato Grosso do Sul - UFMS campus de Três Lagoas Título de Doutor. Av. Ranulpho Leal 3484 - Três Lagoas - MS. CEP 79610-100. Endereço Eletrônico: andreluiz@ceul.ufms.br
} 


\section{INTRODUÇÃO}

O presente trabalho está em fase inicial de pesquisa e elaboração. O Município de Jaraguá do Sul está situado à latitude de 26²9'10"S e à longitude de 4904'00'W (Figura 1). Faz divisa com Campo Alegre, São Bento do Sul ao norte; Blumenau, Massaranduba, Pomerode e Rio dos Cedros ao sul; Guaramirim, Joinville e Schroeder a leste, e com Corupá a oeste. Estando ao norte do Estado de Santa Catarina, no Vale do Itajaí, ou, turisticamente, conhecido como Vale Europeu, é o terceiro pólo industrial do Estado e tem população de 129.970 habitantes (IBGE, 2007). O Rio Itapocu é o principal rio, atravessando a cidade, e tendo com principais afluentes os rios Jaraguá e Itapocuzinho. A área de estudo foi escolhida por localizar-se, em um vale da Serra do Mar que apresenta vulnerabilidade a processos naturais de desnudação que, dadas as condições climáticas, geológicas, geomorfológicas e de ocupação antrópica aumentam o risco de ocorrências de desastres naturais como inundações e movimentos de massa.

O município de Jaraguá do Sul declarou situação de emergência em 20 de novembro de 2008 e, posteriormente, estado de calamidade pública, em 14 de dezembro do mesmo ano. 


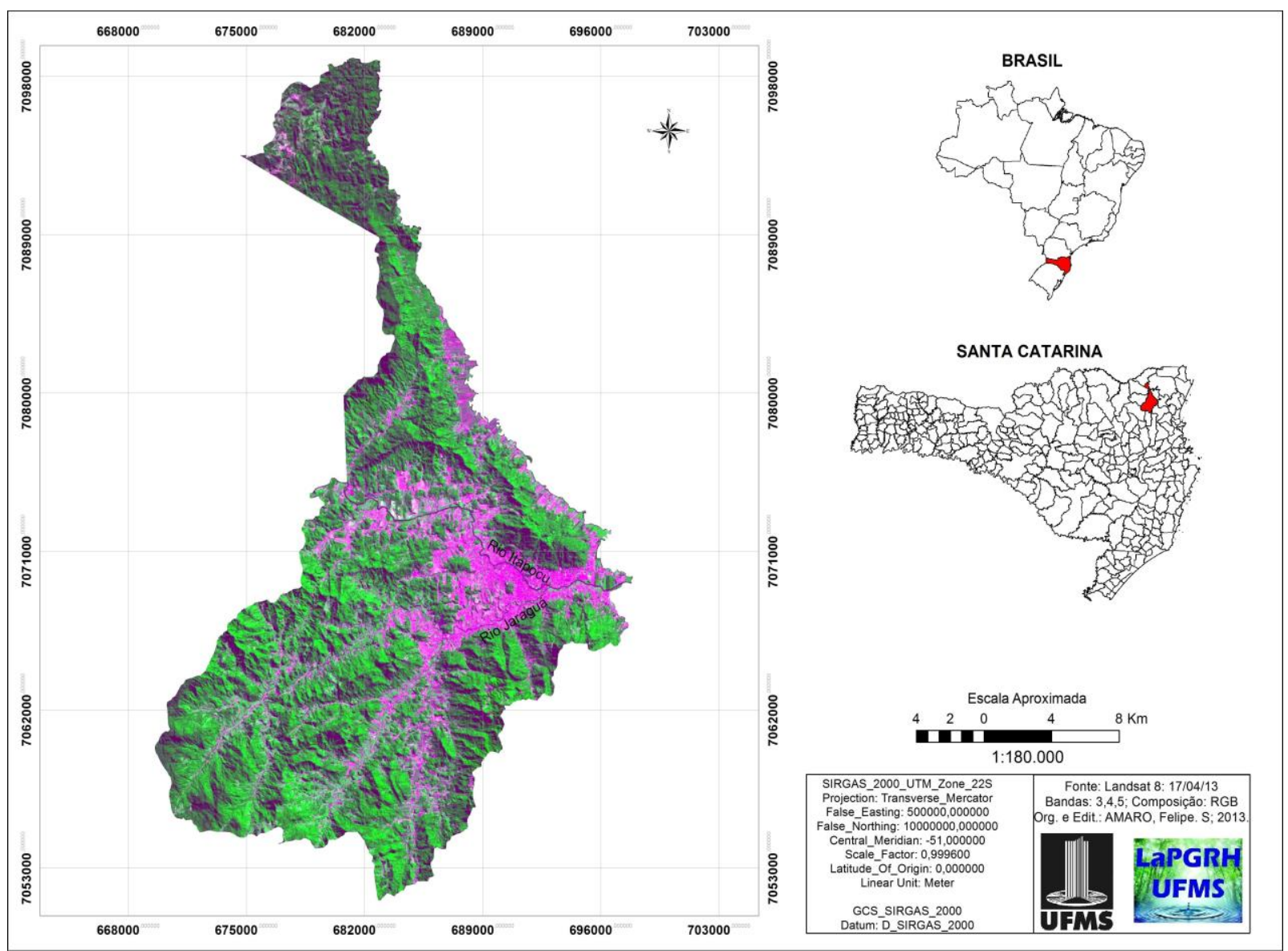

Figura 1: Localização do Município de Jaraguá do Sul - SC Reeditoração e Org: AMARO, F.S 2010

\section{OBJETIVO}

O objetivo do presente trabalho foi o de mapear as ocorrências dos desastres de 2008 e comparar as áreas atingidas com as áreas que haviam sido apontadas como vulneráveis a desastres naturais antes do ocorrido em 2008 , verificando se todas as áreas consideradas anteriormente vulneráveis foram afetadas, e se áreas antes consideradas sem risco foram afetadas com a grande concentração de precipitação do término daquele ano. 


\section{METODOLOGIA}

Para a fase inicial do trabalho, foram realizados o levantamento bibliográfico, 0 levantamento de aspectos hidrológicos e pluviométricos da região e o levantamento dos bairros vulneráveis da cidade e daqueles atingidos em 2008. Para identificar as áreas consideradas de risco antes do ocorrido em 2008, consultou-se a Defesa Civil Municipal de Jaraguá do Sul (SC) e informações da Defesa Civil Estadual. Para o levantamento das áreas atingidas em 2008 foi consultada a Defesa Civil Municipal de Jaraguá do Sul e notícias veiculadas pela mídia.

\section{RESULTADOS PRELIMINARES}

\section{Efeitos das chuvas de 2008 em Santa Catarina}

O evento climático extremo no último trimestre de 2008 em Santa Catarina proporcionou uma elevada precipitação, e devido à sua concentração e continuidade provocou enchentes em áreas de declividade e movimentação de massa nas encostas. Segundo Silva Dias (2009), entre 20 e 24 de novembro ocorreu a maior precipitação do Estado. Desmatamentos, ocupações irregulares em encostas de montanhas, habitações à beira de rios, rodovias mal planejadas, um solo morfológicamente frágil somados às chuvas concentradas, contribuíram diretamente a essa catástrofe; entre os anos de 2000 e 2005 no Estado de Santa Catarina desmatou-se uma área equivalente à cidade de Florianópolis e boa parte ocorreu em encostas e morros (Como evitar... Época, 2008).

Não havia registro de um novembro tão chuvoso nessa região como observado em 2008 quando diversos recordes históricos foram quebrados no triângulo Jaraguá do Sul, Blumenau e Joinville. Os totais do mês ficaram em torno de 1000 mm (SILVA DIAS, 2009); as chuvas registradas no Vale do Itajaí foram classificadas na maior parte do tempo como moderadas, mas com poucas horas sem precipitação, ocasionando um elevado volume de precipitação, saturando o solo da região e inundando áreas. 
As chuvas intensas que ocorreram no Vale do Itajaí incluindo o município de Jaraguá do Sul foram causadas por um bloqueio atmosférico no Oceano Atlântico, acompanhado por um vórtice ciclônico em altitude entre 4000 m e 5000 m, localizados entre o leste de Santa Catarina e o leste do Paraná, que favoreceu a ascensão do ar úmido ao longo do mar (SILVA DIAS, 2009). A combinação desses dois fatores favoreceu a intensificação das chuvas sobre essa região e a persistência do bloqueio fez com que o evento fosse mais agravado ainda, resultando nos grandes volumes de chuva registrados.

O último trimestre de 2008 em Santa Catarina e, especificamente, no Município de Jaraguá do Sul, demonstrou, mais uma vez a vulnerabilidade dessa região. No Estado, segundo a Defesa Civil Estadual, esse desastre afetou 60 municípios e mais de 1,5 milhões de pessoas, com 133 mortes, 22 desaparecidos e mais de 78.000 mil habitantes forçados a deixarem suas casas. Em Jaraguá do Sul, segundo a Defesa Civil Municipal, foram 13 vítimas fatais, sendo 12 vítimas por desmoronamento e 1 vítima por afogamento, além de 147 feridos e aproximadamente 40 famílias desalojadas.

\section{Efeitos das chuvas de 2008 em Jaraguá do Sul (SC)}

As pesquisas da Defesa Civil, no município de Jaraguá do Sul antes da catástrofe de 2008 (Defesa Civil, s/d), apontavam algumas áreas como sendo vulneráveis a enchentes, desmoronamentos e deslizamentos de terra. Foram apontadas áreas de topos de morros, planos, como as áreas onde estão os bairros Santo Antônio, Três Rios do Norte, Três Rios do Sul e Nereu Ramos; e áreas em fundos de vales, com rios permanentes, como as áreas onde estão os bairros Ilha da Figueira, Centenário e Vila Lalau, áreas essas que foram consideradas muito vulneráveis (Figura 2).

O mapeamento dos bairros atingidos na catástrofe de 2008, com base nas informações da Defesa Civil Municipal, mostrou que todas as áreas anteriormente apontadas como vulneráveis foram afetadas e, também, que algumas áreas que não eram propícias a desastres naturais foram afetadas. As áreas onde se localizam os bairros Tiffa Martins, Vila Lenzi e Jaraguá Esquerdo, não foram apontadas como vulneráveis, mas, por estarem localizadas numa baixada, entre dois morros, acabaram por sofrer inundações. 
Outra área, onde se localiza o bairro Barra do Rio Cerro (Foto 1), antes não considerada vulnerável, foi a área mais afetada de toda a cidade, ocorrendo movimento de massa, enchentes e rios transbordados, foi a área com mais mortes e desabrigados da cidade. Uma área da cidade que ficou totalmente isolada foi a do bairro Barra do Rio Molha após a queda de uma ponte que ligava o bairro aos demais da cidade: ocorreram inundações e deslizamentos de terra, deixando moradores totalmente isolados, sem energia elétrica e sem comunicações (Figura 3).

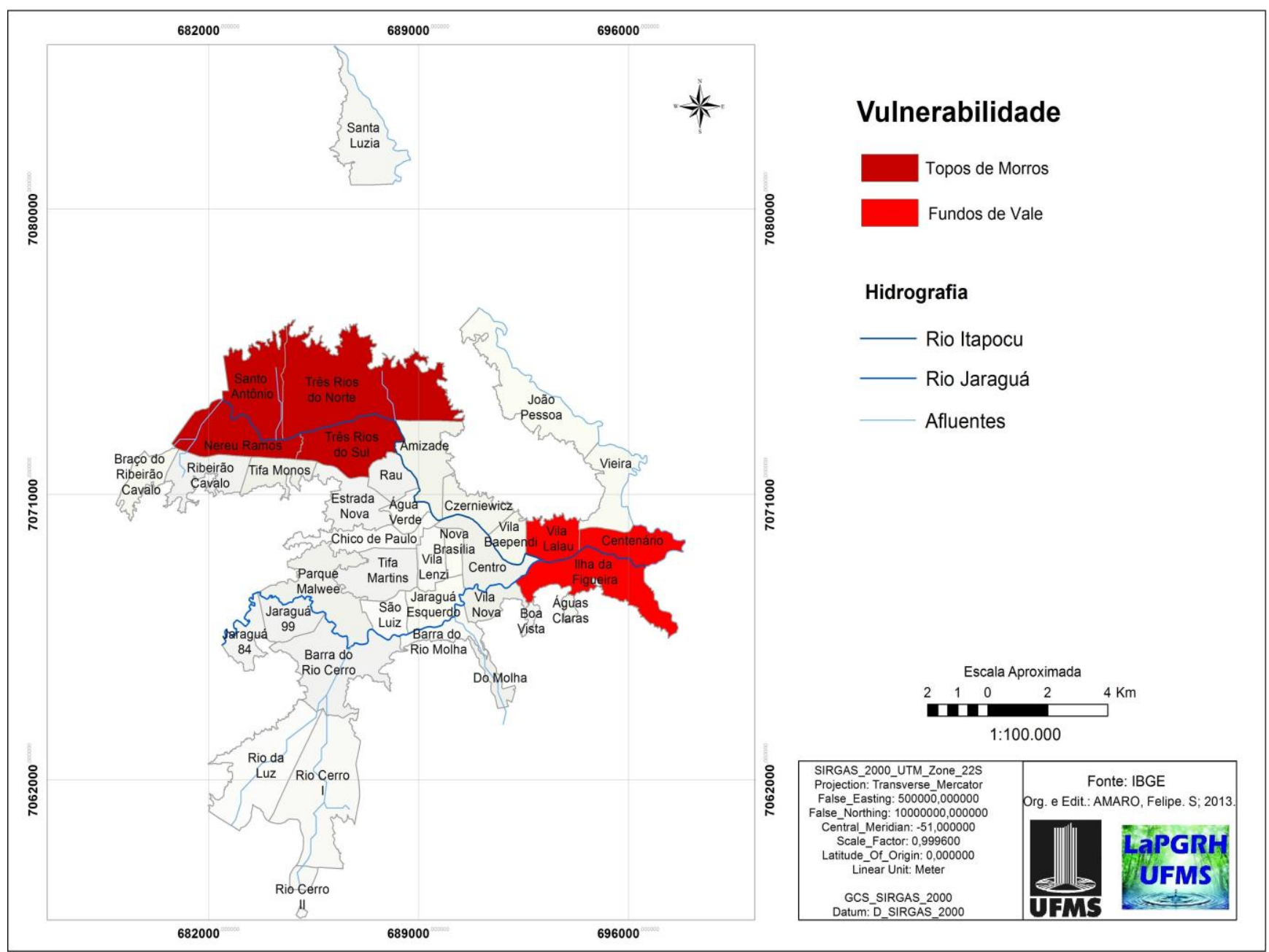

Figura 2: Bairros considerados de risco (adaptado a partir de informações da Defesa Civil Municipal de Jaraguá do Sul - SC (Janeiro/2010) Reeditoração e Org. AMARO, F.S 2010. 


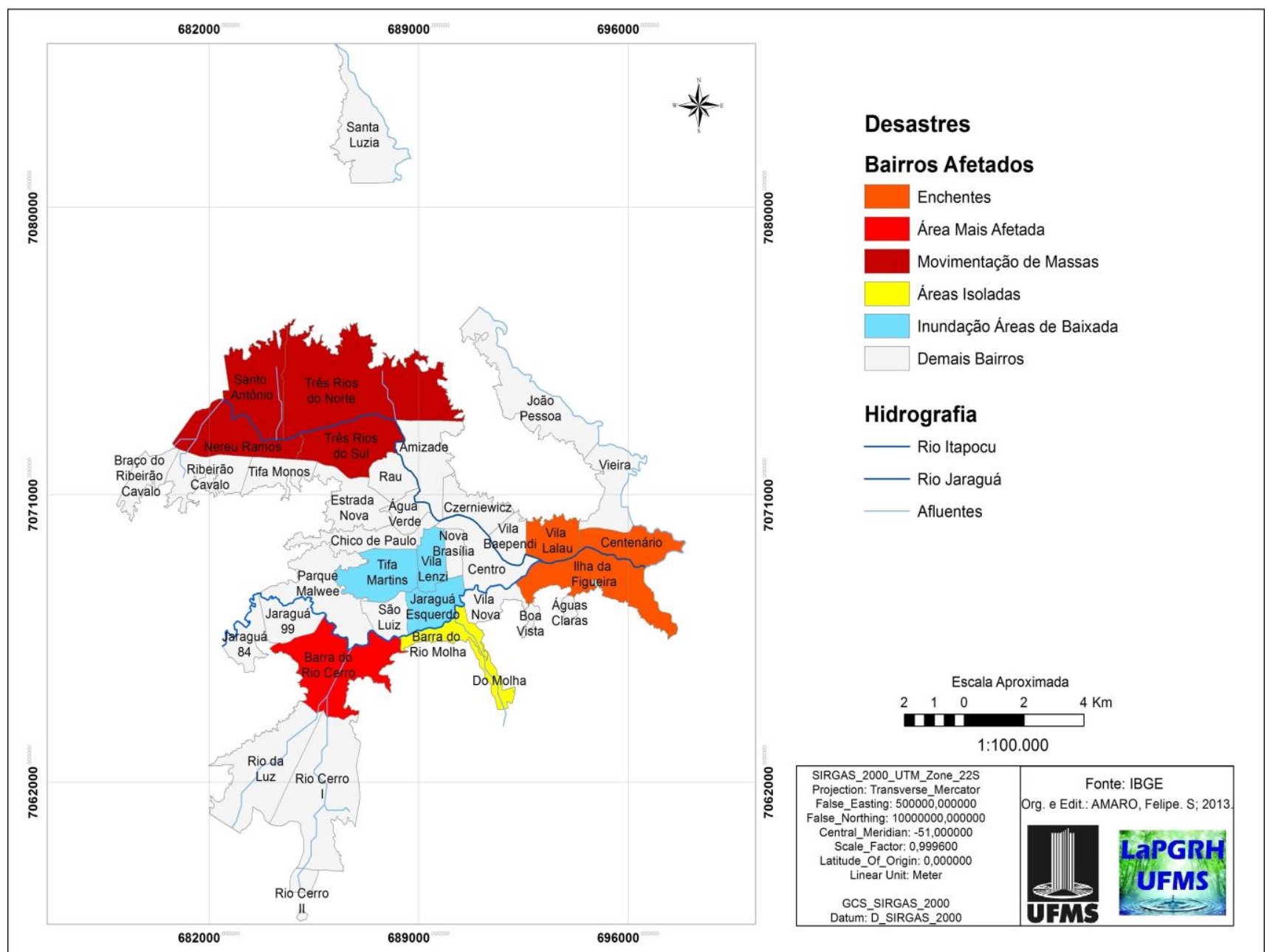

Figura 3: Bairros afetados nos desastres de 2008 em Jaraguá do Sul - SC

Fonte: Defesa Civil e notícias divulgadas na mídia.

Reeditoração e Org. AMARO, F.S 2010.
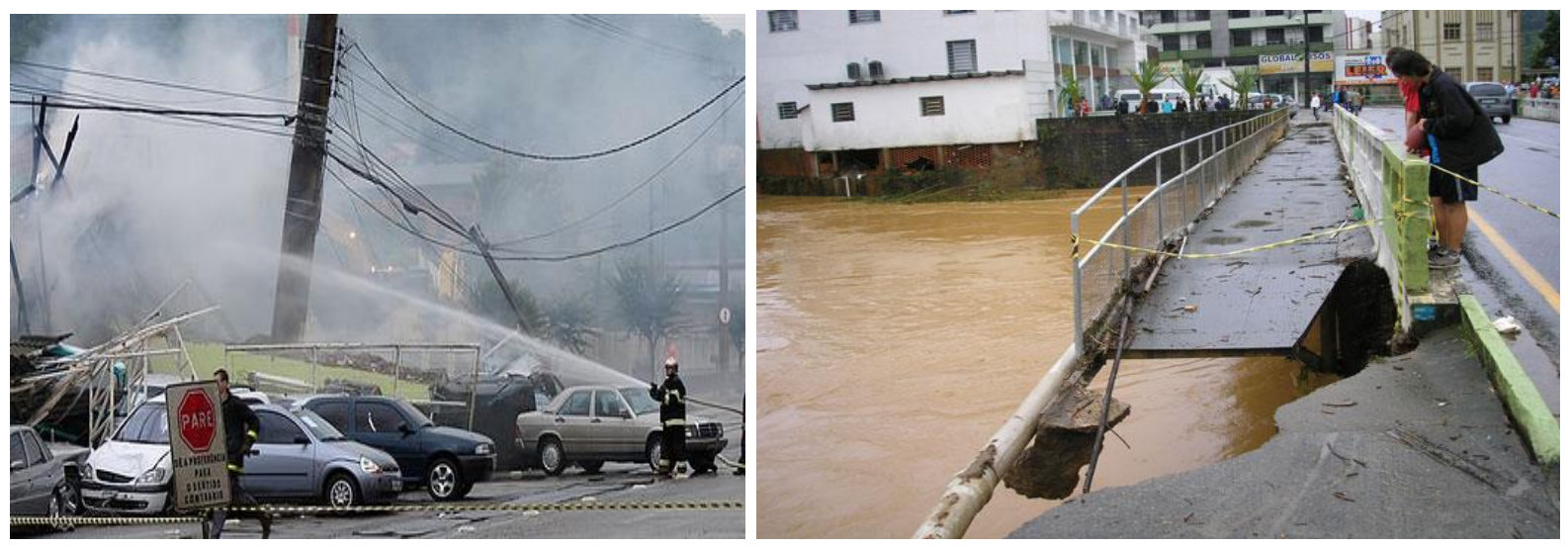

Foto 1 - Deslizamento bairro do Rio Cerro 16/12/2008 /Foto 2 - Ponte sobre o Rio Itapocu - Centro Jaraguá do Sul Org. AMARO, F.S 2010 Fonte: WAG_CBJR (Dez. 2008) /Org. AMARO, F.S 2010 FONTE: TALLINI, R (Nov. 2008). 


\section{Aspectos hidrológicos}

No município de Jaraguá do Sul o Rio Itapocu (Foto 2) chegou a subir 11 metros entre 23 e 24 de novembro de 2008. Esse rio transbordou as barragens de contenção e, em poucas horas elevou-se 11 metros acima do seu nível normal. As chuvas provocaram deslizamentos e desmoronamentos generalizados, que foram responsáveis pela maior parte das fatalidades.

Segundo Silva Dias (2009, p. 42), as inundações no Vale do Itajaí não são novidade; de 1850 a 1992, foram 66 enchentes, das quais 11 até 1900, 20 de 1900 a 1950 e 35 de 1950 a 1992, tornando terras agrícolas e cidades alagadas.

Destaca-se que a configuração topográfica do vale do Rio Itapocu, em Jaraguá do Sul, favorece inundações e, muitas vezes acontecendo de forma abrupta. Dados históricos ressaltam que a intensificação do uso antrópico dessa região só veio agravar os problemas de vulnerabilidade já existentes, tornando cada vez mais comum a ocorrência de desastres nessa região (BERTOLI, 2006, p. 50-51).

\section{CONSIDERAÇÕES FINAIS}

Todos os bairros apontados pela Defesa Civil como vulneráveis foram de fato atingidos pela catástrofe de 2008, e alguns bairros que não eram considerados áreas de risco foram atingidos de alguma forma ou por enchentes ou por deslizamentos, deixando muitas famílias desabrigadas e ocasionando várias mortes no município.

O município como um todo sofreu com a forte concentração de precipitação na região do Vale do Itajaí, com grandes perdas tanto materiais como humanas, servindo de alerta a toda população e principalmente as autoridades, para que se possam criar medidas de prevenção, para que no futuro o município possa estar preparado e melhor equipado para lidar com esse tipo de evento. 
Políticas de remanejamento de famílias que estão em áreas consideradas de risco, de conscientização dessa população sobre os perigos de se morar nessas áreas, aliada à educação ambiental, e de saneamento básico, principalmente na destinação correta dos resíduos sólidos para evitar a obstrução das águas pluviais, são algumas maneiras de se tentar a diminuição de uma possível nova catástrofe no município; juntamente com políticas públicas preocupadas em não impermeabilizar toda área urbana a fim de mitigar os efeitos dos eventos climáticos extremos que possam surgir.

\section{BIBLIOGRAFIA}

BERTOLI, Daiane. Dinâmica da Sub-Bacia do Ribeirão Chico de Paulo (Jaraguá do Sul- SC): Urbanização e Conflitos Decorrentes. Dissertação de Mestrado. Universidade Federal de Santa Catarina (UFSC), Florianópolis, 2006.

Como evitar as enchentes e seus danos. Época. Rio de Janeiro. 22 dez. 2008 http://revistaepoca.globo.com/Revista/Epoca/0,EMl20108-15223,00.html. Acessado em 15/04/2010.

SANTA CATARINA. Defesa Civil do Estado de Santa Catarina, "Dados dos acontecimentos em Jaraguá do Sul a partir de novembro de 2008". Arquivo em Word cedido pela Defesa Civil Municipal de Jaraguá do Sul 22 jan 2010. S/D

Alerta para deslizamentos e alagamentos, 12 nov. 2008. http://www.defesacivil.sc.gov.br/index.php?option=com content\&task=view\&id=486\&ltemid $=262$ Acessado em 24/03/2010

SILVA DIAS, A. F. (Ed.) As chuvas de novembro de 2008 em Santa Catarina: um estudo de caso visando à melhoria do monitoramento e da previsão de eventos extremos. Nota Técnica do Centro de Previsão do Tempo e Estudos Climáticos do Instituto Nacional de Pesquisas Espaciais, sobre os acontecimentos catastróficos de 2008 no estado de Santa Catarina. São José dos Campos - SP, 2009.

TALLINI, Rogério. Enchentes em Santa Catarina 2008. Wordpress, Jaraguá do Sul - SC, 25 nov.2008. http://aleosp2008.wordpress.com/2008/11/25/enchentes-em-santa-catarina2008-as-fotos-falam-por-si/ Acessado em 13/04/2010.

WAG_CBJR. Desastres 11 Jaraguá do Sul - SC. Flickr, Jaraguá do Sul - SC, 16 dez.2008. http://www.flickr.com/photos/8913872@N08/3114032606 Acessado em $19 / 11 / 2009$. 